\title{
A Note on Some Basic Statistical Properties of Beta-HyperLindley Distribution
}

\author{
Akomolafe A. A. ${ }^{{ }^{*}}$ \\ ${ }^{1 *}$ Department of Statistics, Federal University of Technology Akure, Nigeria.
}

\begin{abstract}
This research present the extension of Lindley distribution using Beta distribution to obtain its hybrid version called BetaHyperLindley Distribution. The Beta-HyperLindley Distribution was developed and some of its properties were derived while log-likelihood method of estimation was proposed for parameter estimation. The developed distribution can be used to capture non-normal process because of it statistical significance in modeling and its vast shape ranging from bimodal, highly skewed and heavily tailed.
\end{abstract}

Keywords: Beta-HyperLindley Distribution, log-likelihood, Moment, Hazard, Asymptotic properties

\section{Introduction}

In 1958, Prof. D.V. Lindley (Lindley (1958)) investigated a probability distribution in context of fiducial statistic as a counter example of Bayesian theory. Later, this distribution is called as the Lindley distribution (LD). Ghitany et al. (2008) discussed the fundamental properties of the LD with application to waiting time data. Mazucheli and Achcar (2011) worked on the Lindley distribution applied to competing risks lifetime data. Krishna and Kumar (2011) estimated the parameter of Lindley distribution with progressive Type-II censoring scheme. They also showed that it may be better lifetime model than exponential, lognormal and gamma distributions in some real life situations. Since then the distribution has been widely discussed in various context. Singh and Gupta (2012) have used the Lindley distribution under load sharing sys-tem models. Al-Mutairi et al. (2013) developed the inferential procedure of the stressstrength parameter, when both stress and strength variables follow Lindley distribution. It may be mentioned here that the Lindley distribution is useful when the data show increasing failure rate. This is the properties that encourage the use of Lindley distribution in lifetime data analysis over exponential distribution. Although the family of Lindley distributions possess very nice be restricted to non-monotone hazard rate data (bathtub and upside down bathtub (UBT) see Sharma et al. (2014a)). Therefore, the LD has been extended to various ageing classes and introduced various generalized class of

*Corresponding Author: e-mail: aaakomolafe@futa.edu.ng,

ISSN 2320-7590

(C) 2019 Darshan Institute of Engg. \& Tech., All rights reserved lifetime distribution based on Lindley distribution. Zakerzadeh and Dolati (2009) introduced three parameters extension of the Lindley distribution. Nadarajahet al. (2011), Ghitany et al. (2013) proposed two parameter generalizations of the Lindley distribution, called as the generalized Lindley and power Lindley distributions. These distributions are generated using the exponentiation and power transformations to the Lindley distribution. Merovci (2013) and Merovci and Elbatal (2014) investigated transmuted Lindley and transmuted Lindley-geometric distributions respectively. The beta-Lindley distribution is introduced by Merovci and Sharma (2014). Statistical and mathematical properties of Kumaraswamy Quasi Lindley and Kumaraswamy Lindley distributions are discussed by Elbatal and Elgarhy (2013) and Akmakyapan and Kadlar (2014) respectively. The exponentiated power Lindley distribution is introduced by Ashour and Eltehiwy (2015). The generalized Poisson-Lindley and another extension of the Lindley distribution are discussed by Mahmoudi and Zakerzadeh (2010) and Oluyede and Yang (2015).

\subsection{Derivation of HyperLindely Distribution}

Let $\mathrm{X}$ be a random variable that follow Lindley Distribution, then it's hyper-family of distribution can be derive as defined by equation(1)

$g\left(x ; \theta_{i}\right)=\sum_{i=1}^{n} p_{i} \frac{\theta_{i}^{2}}{\left(\theta_{i}+1\right)}(1+x) e^{-\theta_{i} x}$ 
$g\left(x ; \theta_{1}, \theta_{2}\right)=p \frac{\theta_{1}{ }^{2}}{\left(\theta_{1}+1\right)}(1+x) e^{-\theta_{1} x}+q \frac{\theta_{2}{ }^{2}}{\left(\theta_{2}+1\right)}(1+x) e^{-\theta_{2} x}$

By integrating (2) over its support, we obtain the CDF of this distribution $G\left(x ; \theta_{1}, \theta_{1}\right)=\int_{0}^{t} g\left(x ; \theta_{1}, \theta_{2}\right) d x$ and this can be shown by

$G\left(x ; \theta_{1}, \theta_{1}\right)=p\left(1-\frac{e^{-\theta_{1} x}\left(1+\theta_{1}+\theta_{1} x\right)}{\left(1+\theta_{1}\right)}\right)+q\left(1-\frac{e^{-\theta_{2} x}\left(1+\theta_{2}+\theta_{2} x\right)}{\left(1+\theta_{2}\right)}\right)$

The (2) and (3) above are the PDF and CDF of HyperLindley Distribution

\subsection{Moment}

Now let us consider the different moments of the BetaHyperLindley Distribution. Suppose X denote the transmuted Lindley distribution random variable with parameters $\theta_{1}$ and $\theta_{2}$, then

$$
\begin{aligned}
E^{r} & =\int_{0}^{\infty} x^{r} g\left(x ; \theta_{1}, \theta_{2}\right) d x \\
& =\int_{0}^{\infty} x^{r}\left(p \frac{\theta_{1}{ }^{2}}{\left(\theta_{1}+1\right)}(1+x) e^{-\theta_{1} x}+q \frac{\theta_{2}{ }^{2}}{\left(\theta_{2}+1\right)}(1+x) e^{-\theta_{2} x}\right) d x \\
& =p \frac{1}{\theta_{1}{ }^{r}\left(\theta_{1}+1\right)} \int_{0}^{\infty} \theta_{1} y^{r} e^{-y} d y+y^{r+1} e^{-y} d y+ \\
& q \frac{1}{\theta_{2}{ }^{r}\left(\theta_{2}+1\right)} \int_{0}^{\infty} \theta_{2} z^{r} e^{-z} d z+z^{r+1} e^{-z} d z \\
& p \frac{1}{\theta_{1}{ }^{r}\left(\theta_{1}+1\right)}\left[\theta_{1} \Gamma(r+1)+\Gamma(r+2)\right]+ \\
& q \frac{1}{\theta_{2}{ }^{r}\left(\theta_{2}+1\right)}\left[\theta_{2} \Gamma(r+1)+\Gamma(r+2)\right]
\end{aligned}
$$

When $r=1,2,3,4$ respectively becomes

$$
\begin{gathered}
\mathrm{Ex}=\frac{p\left(\theta_{1}+2\right)}{\theta_{1}\left(\theta_{1}+1\right)}+\frac{q\left(\theta_{2}+2\right)}{\theta_{2}\left(\theta_{2}+1\right)} \\
\mathrm{Ex}^{2}=\frac{2 \mathrm{p}\left(\theta_{1}+3\right)}{\theta_{1}^{2}\left(\theta_{1}+1\right)}+\frac{2 \mathrm{q}\left(\theta_{2}+3\right)}{\theta_{2}{ }^{2}\left(\theta_{2}+1\right)} \\
\mathrm{Ex}^{3}=\frac{6 \mathrm{p}\left(\theta_{1}+4\right)}{\theta_{1}^{2}\left(\theta_{1}+1\right)}+\frac{6 q\left(\theta_{2}+4\right)}{\theta_{2}^{2}\left(\theta_{2}+1\right)} \\
\mathrm{Ex}^{4}=\frac{24 p\left(\theta_{1}+5\right)}{\theta_{1}^{2}\left(\theta_{1}+1\right)}+\frac{24 q\left(\theta_{2}+5\right)}{\theta_{2}{ }^{2}\left(\theta_{2}+1\right)}
\end{gathered}
$$

\section{Variance}

$$
\operatorname{Var}(\mathrm{x})=\mathrm{Ex}^{2}-(\mathrm{Ex})^{2}
$$

$$
\operatorname{Var}(\mathrm{x})=\frac{\mathrm{p}\left(\theta_{1}{ }^{2}+4 \theta_{1}+2\right)}{\theta_{1}^{2}\left(\theta_{2}+1\right)^{2}}+\frac{p\left(\theta_{1}{ }^{2}+4 \theta_{1}+2\right)}{\theta_{1}^{2}\left(\theta_{2}+1\right)^{2}}
$$

\subsection{Derivation and Development of Beta-HyperLindley Distribution}

Now by using the logit of beta defined by Jones, the mixture of Beta-HyperLindley distribution can be obtained. Now let $\mathrm{X}$ be a random variable from the distribution with parameters $\left(\theta_{1}, \theta_{2}\right)$ and defined by $\mathrm{g}\left(\mathrm{x} ; \theta_{1}, \theta_{2}\right)$ and $\mathrm{G}\left(\mathrm{x} ; \theta_{1}, \theta_{2}\right)$ using the logit of Beta defined by Jones

$$
\mathrm{f}_{\text {BHLD }}\left(\mathrm{x} ; \mathrm{a}, \mathrm{b}, \theta_{1}, \theta_{2}\right)=\frac{1}{\mathrm{~B}(\mathrm{a}, \mathrm{b})}[\mathrm{G}(\mathrm{x})]^{\mathrm{a}-1}[1-\mathrm{G}(\mathrm{x})]^{\mathrm{b}-1} \mathrm{~g}(\mathrm{x})
$$

Where,

$$
\begin{aligned}
& \mathrm{g}\left(\mathrm{x} ; \theta_{1}, \theta_{2}\right)=\mathrm{p} \frac{\theta_{1}^{2}}{\left(\theta_{1}+1\right)}(1+\mathrm{x}) \mathrm{e}^{-\theta_{1} \mathrm{x}}+\mathrm{q} \frac{\theta_{2}^{2}}{\left(\theta_{2}+1\right)}(1+\mathrm{x}) \mathrm{e}^{-\theta_{2} \mathrm{x}} \text { and } \\
& \mathrm{G}\left(\mathrm{x} ; \theta_{1}, \theta_{2}\right)=\mathrm{p}\left(1-\frac{\mathrm{e}^{-\theta_{1} \mathrm{x}}\left(1+\theta_{1}+\theta_{1} \mathrm{x}\right)}{\left(1+\theta_{1}\right)}\right)+\mathrm{q}\left(1-\frac{\mathrm{e}^{-\theta_{2} \mathrm{x}}\left(1+\theta_{2}+\theta_{2} \mathrm{x}\right)}{\left(1+\theta_{2}\right)}\right)
\end{aligned}
$$

are the pdf and cdf of Hjorth Distribution respectively. Then the Beta-HyperLindley Distribution is obtained by using (13) are shown by (14).

$$
\begin{aligned}
& \left\{\frac{1}{\mathrm{~B}(\mathrm{a}, \mathrm{b})}\left(\mathrm{p}\left(1-\frac{\mathrm{e}^{-\theta_{1} \mathrm{x}}\left(1+\theta_{1}+\theta_{1} \mathrm{x}\right)}{\left(1+\theta_{1}\right)}\right)+\mathrm{q}\left(1-\frac{\mathrm{e}^{-\theta_{2} \mathrm{x}}\left(1+\theta_{2}+\theta_{2} \mathrm{x}\right)}{\left(1+\theta_{2}\right)}\right)\right)^{\mathrm{a}-1}\right. \\
& \left.1-\left[\mathrm{p}\left(1-\frac{\mathrm{e}^{-\theta_{1} \mathrm{x}}\left(1+\theta_{1}+\theta_{1} \mathrm{x}\right)}{\left(1+\theta_{1}\right)}\right)+\mathrm{q}\left(1-\frac{\mathrm{e}^{-\theta_{2} \mathrm{x}}\left(1+\theta_{2}+\theta_{2} \mathrm{x}\right)}{\left(1+\theta_{2}\right)}\right)\right]\right)^{\mathrm{b}-1} . \\
& \left.\mathrm{p} \frac{\theta_{1}^{2}}{\left(\theta_{1}+1\right)}(1+\mathrm{x}) \mathrm{e}^{-\theta_{1} \mathrm{x}}+\mathrm{q} \frac{\theta_{2}{ }^{2}}{\left(\theta_{2}+1\right)}(1+\mathrm{x}) \mathrm{e}^{-\theta_{2} \mathrm{x}}\right\}
\end{aligned}
$$

The equation (15) above is the pdf of Beta-HyperLindley Distribution (BHLD), while the cdf is as shown below:

$\mathrm{F}_{\mathrm{BHLD}}\left(\mathrm{x} ; \mathrm{a}, \mathrm{b}, \theta_{1}, \theta_{2}\right)=$

$$
\begin{aligned}
& \int_{0}^{x} \frac{1}{B(a, b)}\left(p\left(1-\frac{e^{-\theta_{1} x}\left(1+\theta_{1}+\theta_{1} x\right)}{\left(1+\theta_{1}\right)}\right)\right. \\
& \left.+q\left(1-\frac{e^{-\theta_{2} x}\left(1+\theta_{2}+\theta_{2} x\right)}{\left(1+\theta_{2}\right)}\right)\right)^{a-1} . \\
& \left(1-\left(p\left(1-\frac{e^{-\theta_{1} x}\left(1+\theta_{1}+\theta_{1} x\right)}{\left(1+\theta_{1}\right)}\right)\right.\right.
\end{aligned}
$$


$\left.\left.+q\left(1-\frac{\mathrm{e}^{-\theta_{2} \mathrm{x}}\left(1+\theta_{2}+\theta_{2} \mathrm{x}\right)}{\left(1+\theta_{2}\right)}\right)\right]\right)^{\mathrm{b}-1}$.
$\mathrm{p} \frac{\theta_{1}^{2}}{\left(\theta_{1}+1\right)}(1+\mathrm{x}) \mathrm{e}^{-\theta_{1} \mathrm{x}}+\mathrm{q} \frac{\theta_{2}^{2}}{\left(\theta_{2}+1\right)}(1+\mathrm{x}) \mathrm{e}^{-\theta_{2} \mathrm{x}} \mathrm{dx}$

From equation (14), it follows that;

$\mathrm{F}_{\mathrm{BHLD}}\left(\mathrm{x} ; \mathrm{a}, \mathrm{b}, \theta_{1}, \theta_{2}\right)=\int_{0}^{t} \frac{1}{\mathrm{~B}(\mathrm{a}, \mathrm{b})} \mathrm{K}^{\mathrm{a}-1}(1-\mathrm{K})^{\mathrm{b}-1} \mathrm{dz}$

Where $\mathrm{K}$ is the cdf of parent distribution, by following the approach of incomplete beta function, which states

$B(x ; \alpha, \beta)=\int_{0}^{t} x^{\alpha-1}(1-x)^{\beta-1}$

From this expression we can conclude that

$\int_{0}^{t} \frac{1}{\mathrm{~B}(\mathrm{a}, \mathrm{b})} \mathrm{K}^{\mathrm{a}-1}(1-\mathrm{K})^{\mathrm{b}-1} \mathrm{dz}=\frac{\mathrm{B}(\mathrm{K} ; \mathrm{a}, \mathrm{b})}{\mathrm{B}(\mathrm{a}, \mathrm{b})}=\mathrm{I}_{\mathrm{K}}(\mathrm{a}, \mathrm{b})$
Where $\operatorname{IK}(\mathrm{a}, \mathrm{b})$ is the regularized incomplete beta function and $\mathrm{K}$ is the cdf of the parent distribution.

$\mathrm{F}_{\mathrm{BHLD}}(\mathrm{K})=\mathrm{I}_{\mathrm{K}}(\mathrm{a}, \mathrm{b})=\frac{\mathrm{B}(\mathrm{K} ; \mathrm{a}, \mathrm{b})}{\mathrm{B}(\mathrm{a}, \mathrm{b})}$

Therefore, equation (15) and equation (16) are the probability distribution function [pdf] and cumulative distribution function[cdf] of Beta-HyperLindley Distribution respectively.

\subsection{Reliability}

The reliability function $\mathrm{R}(\mathrm{x})$, which is the probability of an item not failing prior to sometime $t$, is defined by $R(t)=1-$ $\mathrm{F}(\mathrm{t})$. The reliability function of Beta-HyperLindley Distribution is given by

$\mathrm{R}(\mathrm{t})=1-\mathrm{F}_{\text {BHLD }}(\mathrm{M})=1-\frac{\mathrm{B}(\mathrm{K} ; \mathrm{a}, \mathrm{b})}{\mathrm{B}(\mathrm{a}, \mathrm{b})}=\frac{\mathrm{B}(\mathrm{a}, \mathrm{b})-\mathrm{B}(\mathrm{K} ; \mathrm{a}, \mathrm{b})}{\mathrm{B}(\mathrm{a}, \mathrm{b})}$

\subsection{Hazard Function}

Hazard function is represented in mathematical form as

$$
\begin{aligned}
& H(x)= \\
& \frac{1}{B(a, b)}\left(p\left(1-\frac{e^{-\theta_{1} x}\left(1+\theta_{1}+\theta_{1} x\right)}{\left(1+\theta_{1}\right)}\right)+q\left(1-\frac{e^{-\theta_{2} x}\left(1+\theta_{2}+\theta_{2} x\right)}{\left(1+\theta_{2}\right)}\right)\right)^{a-1}\left(1-\left[p\left(1-\frac{e^{-\theta_{1} x}\left(1+\theta_{1}+\theta_{1} x\right)}{\left(1+\theta_{1}\right)}\right)+q\left(1-\frac{e^{-\theta_{2} x}\left(1+\theta_{2}+\theta_{2} x\right)}{\left(1+\theta_{2}\right)}\right)\right]\right)^{b-1} \\
& \mathrm{p} \frac{\theta_{1}^{2}}{\left(\theta_{1}+1\right)}(1+\mathrm{x}) \mathrm{e}^{-\theta_{1} \mathrm{x}}+\mathrm{q} \frac{\theta_{2}^{2}}{\left(\theta_{2}+1\right)}(1+\mathrm{x}) \mathrm{e}^{-\theta_{2} \mathrm{x}} \\
& \frac{B(a, b)-B(M ; a, b)}{B(a, b)} \\
& =\left[\frac{1}{B(a, b)}\left(p\left(1-\frac{e^{-\theta_{1} x}\left(1+\theta_{1}+\theta_{1} x\right)}{\left(1+\theta_{1}\right)}\right)+q\left(1-\frac{e^{-\theta_{2} x}\left(1+\theta_{2}+\theta_{2} x\right)}{\left(1+\theta_{2}\right)}\right)\right)^{a-1}\left(1-\left[p\left(1-\frac{e^{-\theta_{1} x}\left(1+\theta_{1}+\theta_{1} x\right)}{\left(1+\theta_{1}\right)}\right)+q\left(1-\frac{e^{-\theta_{2} x}\left(1+\theta_{2}+\theta_{2} x\right)}{\left(1+\theta_{2}\right)}\right]\right)\right]^{b-1}\right] \\
& x p \frac{\theta_{1}^{2}}{\left(\theta_{1}+1\right)}(1+x) e^{-\theta_{1} x}+q \frac{\theta_{2}^{2}}{\left(\theta_{2}+1\right)}(1+x) e^{-\theta_{2} x} x \frac{B(a, b)}{B(a, b)-B(M ; a, b)} \\
& {\left[\frac{1}{B(a, b)}\left(p\left(1-\frac{e^{-\theta_{1} x}\left(1+\theta_{1}+\theta_{1} x\right)}{\left(1+\theta_{1}\right)}\right)+q\left(1-\frac{e^{-\theta_{2} x}\left(1+\theta_{2}+\theta_{2} x\right)}{\left(1+\theta_{2}\right)}\right)\right)^{a-1}\left(1-\left[p\left(1-\frac{e^{-\theta_{1} x}\left(1+\theta_{1}+\theta_{1} x\right)}{\left(1+\theta_{1}\right)}\right)+q\left(1-\frac{e^{-\theta_{2} x}\left(1+\theta_{2}+\theta_{2} x\right)}{\left(1+\theta_{2}\right)}\right]\right)\right]\right.} \\
& x p \frac{\theta_{1}^{2}}{\left(\theta_{1}+1\right)}(1+x) e^{-\theta_{1} x}+q \frac{\theta_{2}^{2}}{\left(\theta_{2}+1\right)}(1+x) e^{-\theta_{2} x} \\
& B(a, b)-B(M ; a, b)
\end{aligned}
$$




\subsection{Moment}

According to Cordeiro and De castro, the moment generating function of $\gamma$ generated beta distribution is display above gives

$$
M_{x}(t)=\frac{1}{B(a, b)} \sum_{i=1}^{n}(-1)^{i}\left(\begin{array}{c}
b-1 \\
i
\end{array}\right) \rho(t, a i-1)
$$

where, $\rho(t, r)=\int_{-\infty}^{\infty} e^{t x}[F(x)]^{r} f(x) d x$

$$
M_{x}(t)=\frac{1}{B(a, b)} \sum_{i=1}^{n}(-1)^{i}\left(\begin{array}{c}
b-1 \\
i
\end{array}\right) \int_{-\infty}^{\infty} e^{t x}[F(x)]^{r} f(x) d x
$$

$\mathrm{M}_{\mathrm{x}}(\mathrm{t})=$

$$
\begin{aligned}
& \frac{1}{\mathrm{~B}(\mathrm{a}, \mathrm{b})} \sum_{\mathrm{i}=1}^{\mathrm{n}}(-1)^{\mathrm{i}}\left(\begin{array}{c}
\mathrm{b}-1 \\
\mathrm{i}
\end{array}\right) . \\
& \int_{0}^{\infty}\left[\mathrm{p}\left(1-\frac{\mathrm{e}^{-\theta_{1} \mathrm{x}}\left(1+\theta_{1}+\theta_{1} \mathrm{x}\right)}{\left(1+\theta_{1}\right)}\right)+\mathrm{q}\left(1-\frac{\mathrm{e}^{-\theta_{2} \mathrm{x}}\left(1+\theta_{2}+\theta_{2} \mathrm{x}\right)}{\left(1+\theta_{2}\right)}\right)\right]^{\mathrm{r}} . \\
& \mathrm{p} \frac{\theta_{1}^{2}}{\left(\theta_{1}+1\right)}(1+\mathrm{x}) \mathrm{e}^{-\theta_{1} \mathrm{x}}+\mathrm{q} \frac{\theta_{2}^{2}}{\left(\theta_{2}+1\right)}(1+\mathrm{x}) \mathrm{e}^{-\theta_{2} \mathrm{x}} \mathrm{dx}
\end{aligned}
$$

Let $\mathrm{i}=1$, the mgf of Beta-Hyperlindly becomes the mgf of the parent distribution (HyperLindly Distribution)

\section{Parameter Estimation using Log-likelihoodmethod}

Codeiro et al (2011), stated equation (26) as the loglikelihood estimation method for estimating parameter $\beta=$ $(\mathrm{a}, \mathrm{b}, \mathrm{c}, \tau)$, where $\tau$ is the parameter vector of the parent distribution.

$$
\begin{aligned}
& \mathrm{l}(\theta)=\text { nlogc-nlog }[\mathrm{B}(\mathrm{a}, \mathrm{b})]+\sum_{\mathrm{i}=1}^{\mathrm{n}} \operatorname{logf}\left(\mathrm{x}_{\mathrm{i}}, \tau\right)+ \\
& \quad(\mathrm{a}-1) \sum_{\mathrm{i}=1}^{\mathrm{n}} \log \mathrm{F}\left(\mathrm{x}_{\mathrm{i}}, \tau\right)+(\mathrm{b}-1) \sum_{\mathrm{i}=1}^{\mathrm{n}} \log \left(1-\mathrm{F}\left(\mathrm{x}_{\mathrm{i}}, \tau\right)\right)
\end{aligned}
$$

The generalized distribution reduces to the class of beta generated distribution when $\mathrm{c}=1$, and the parameter vector $\beta$ become $\beta=(a, b, \theta, \alpha)$.

$$
\begin{gathered}
\mathrm{l}(\beta)=-\operatorname{nlog}[\mathrm{B}(\mathrm{a}, \mathrm{b})]+\sum_{\mathrm{i}=1}^{\mathrm{n}} \operatorname{logf}\left(\mathrm{x}_{\mathrm{i}}, \tau\right)+(\mathrm{a}-1) \sum_{\mathrm{i}=1}^{\mathrm{n}} \log \mathrm{F}\left(\mathrm{x}_{\mathrm{i}}, \tau\right)+ \\
(\mathrm{b}-1) \sum_{\mathrm{i}=1}^{\mathrm{n}} \log \left(1-\mathrm{F}\left(\mathrm{x}_{\mathrm{i}}, \tau\right)\right)
\end{gathered}
$$

By making necessary substitution, (27) becomes (28).

$l(\beta)=$

$$
\begin{aligned}
& -\operatorname{nlog}[B(a, b)]+ \\
& \sum_{i=1}^{n} \log \left(p \frac{\theta_{1}{ }^{2}}{\left(\theta_{1}+1\right)}(1+x) e^{-\theta_{1} x}+q \frac{\theta_{2}{ }^{2}}{\left(\theta_{2}+1\right)}(1+x) e^{-\theta_{2} x}\right)+
\end{aligned}
$$

$$
\begin{aligned}
& \text { (a-1) } \sum_{i=1}^{n} \log \left(p\left(1-\frac{\mathrm{e}^{-\theta_{1} \mathrm{x}}\left(1+\theta_{1}+\theta_{1} \mathrm{x}\right)}{\left(1+\theta_{1}\right)}\right)+\mathrm{q}\left(1-\frac{\mathrm{e}^{-\theta_{2} \mathrm{x}}\left(1+\theta_{2}+\theta_{2} \mathrm{x}\right)}{\left(1+\theta_{2}\right)}\right)\right)+ \\
& \text { (b-1) } \sum_{\mathrm{i}=1}^{\mathrm{n}} \log \left(1-\left(\mathrm{p}\left(1-\frac{\mathrm{e}^{-\theta_{1} \mathrm{x}}\left(1+\theta_{1}+\theta_{1} \mathrm{x}\right)}{\left(1+\theta_{1}\right)}\right)+\mathrm{q}\left(1-\frac{\mathrm{e}^{-\theta_{2} \mathrm{x}}\left(1+\theta_{2}+\theta_{2} \mathrm{x}\right)}{\left(1+\theta_{2}\right)}\right)\right)\right)
\end{aligned}
$$

\section{Plot of Beta-Hyperlindley Distribution(BHLD)}

The shape of the probability distribution function and cumulative distribution function of Beta-hyperlindley Distribution with selected parameter values are shown in Figure 1 and Figure 2 respectively.

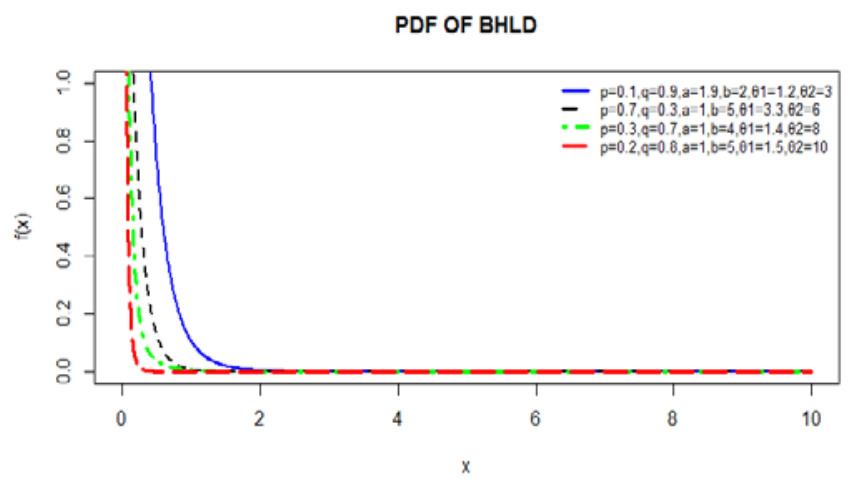

Figure 1. The graph of probability distribution function of Beta-HyperLindley Distribution

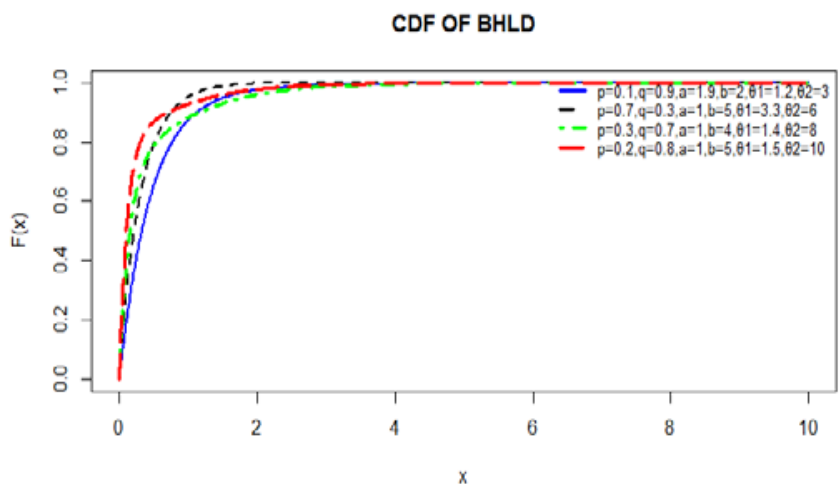

Figure 2. The graph of cummulative distribution function of Beta-HyperLindley Distribution

The figure below shows the reliability plot of the distribution indicating the reliability function decreasing with increasing of $x$ at different values of $\theta_{1}$ and $\theta_{2}$ and fixed values of $a$.

Figure 4 shows the hazard rate function is slowly increasing at increasing of $\mathrm{x}$ and different values of $\theta_{1}$ and $\theta_{2}$ and fixed values of a. 


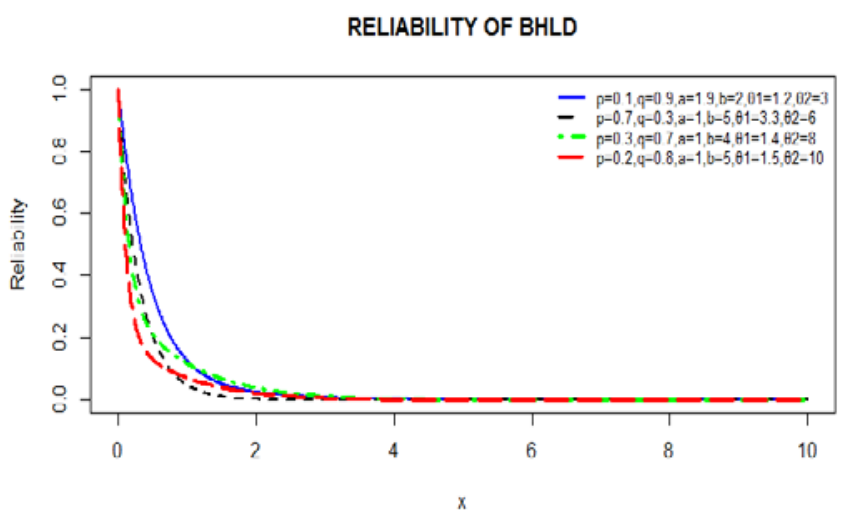

Figure 3. The graph of reliability plot of Beta-HyperLindley Distribution

HAZRAD PLOT (BHLD)

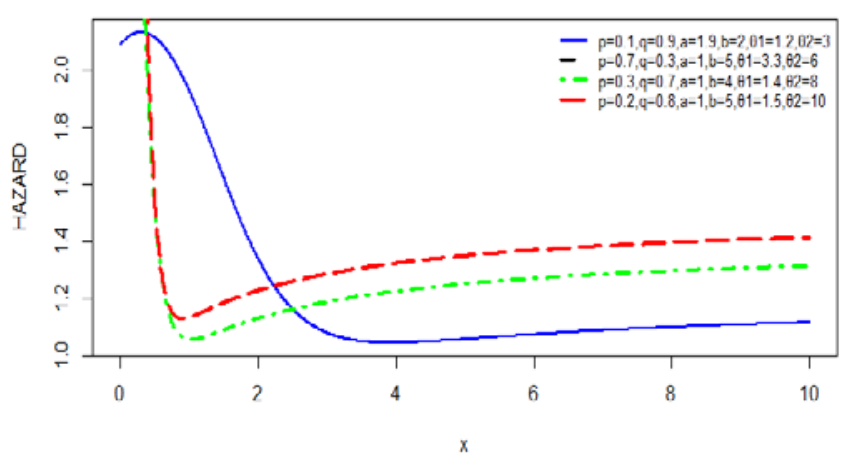

Figure 4. The graph of harzard plot of Beta-HyperLindley Distribution

The implementation of consistency of Beta Hyper Lindley Distributionin tracking purchasing pattern onthe secondary data collected for some products (TrophyLager Beer, Castle Milk Stout, Castle lager, HeroLager Beer, MGD RB 600mlx12, Eagle Lager,Betamalt, Grand Malt, AFB and Voltic Water from International Breweries) for ten years.

4.1 Precision: If the precision parameter $\mathrm{S}<1$, then the model is adequate and consistent for the buying behavior data, it is not consistent if otherwise. Since the precision parameter $S(0.004487474)<1$, then Beta Hyper Lindley Distribution [BHLD] is consistent and efficient as compared to Beta Lindley Distribution [BLD]. Due to the extension, the adequacy of the model has improved significantly, Since the parameter of the model constitute over $93.2 \%$ to the model, the adequacy and its predictive estimate can be totally relied on in decision making and prospective planning.

\subsection{Comparison Criteria for Beta Lindley Distribution and Beta Hyper Lindley Distribution}

Table 1a: Shows comparative criteria for Beta Lindley Distribution [BLD] and Beta Hyper Lindley Distribution [BHLD]
Table 1. Comparison between BLD and BHLD

\begin{tabular}{|c|c|c|}
\hline & $\begin{array}{c}\text { Bayes Factor } \\
(10<\mathrm{BF}<30)\end{array}$ & $\begin{array}{c}\text { Precison Parameter } \\
{[\mathrm{S}<1]}\end{array}$ \\
\hline BHLD & $\begin{array}{c}16.3421 \\
\text { [It has a better fit] }\end{array}$ & $\begin{array}{c}0.00449 \\
\text { [Highly consistence and } \\
\text { efficient] }\end{array}$ \\
\hline BLD & 25.9881 & 1.46129 \\
\hline
\end{tabular}

Table 2: Shows comparative criteria for BLD and BHLD using Akaike information criteria [AIC] and Bayesian information criteria [BIC].

Table 2. Comparison between BLD and BHLD using AIC and BIC

\begin{tabular}{|c|c|c|}
\hline & BLD & BHLD \\
\hline AIC & 1138.99 & 390.04 \\
\hline BIC & 1473.23 & 131.453 \\
\hline
\end{tabular}

From the tables above, it can be deduced that the BHLD fits the purchase data reasonably well. The Predictive Beta Hyper Lindley Distribution stands the test of Akaike information criteria [AIC] and Bayesian information criteria [BIC]. This test states that model with the lowest AIC and BIC will produce best result when fitted to the data sets. BHLD is efficient for predicting the expected sales volume and the general behavior of the sales pattern in the prospective marketing period, thus it is also much more consistent and efficient as compared to BLD.

\section{Conclusions}

The model provides a significant improvementin fit and modeling. It is an importantmodel for analysis of lifetime data because of the wide usage of the lindleydistribution and the fact that the current generalization provides means of itscontinuous extension to more complexsituations. We provide a comprehensive description of some structural properties of the proposed distribution with the hopethat it will attract wider applications in several fields. The estimation ofparameters is approached by the method of maximum likelihood. The usefulness of the new models can be illustrated using real data sets. The proposed models provide a ratherflexible mechanism for fitting a wide spectrum of positive real data sets.

\section{References}

1. Aarset, V.M.1987. "How to identify bathtub hazard rate.”IEEE Transactions on Reliability 36(1):106108.doi: 10.1109/TR.1987.5222310

2. Akinsete, A., F. Famoye and C. Lee. 2008. "The beta- pareto distribution." Journal of Theoretical and Applied Statistics 42(6):547-563. doi.org/10.1080/02331880801983876

3. Akomolafe, A.A and A. Maradesa. 2017. "Betahalfnormal Distribution and Its Properties." International journal of Advance Research and Publication 1(4): pp. 17-22. 
4. Akomolafe, A.Aand Awogbemi, C.A. (2017): Evaluation of Demographic Pattern of Asthma Patients in Nigeria: Insight from a Multilevel Analysis. The Pacific Journal of Science and Technology.18(2), pp. 292 - 304

5. Akomolafe, A. A. and Yussuf, T. O. (2018). Dirichilet- Multinomial Model: its mixture and Application using Bayesian Approach. Rep Opinion 10(2),pp. 1-15. http://www.sciencepub.net/reportdoi: 10:7517/marsroj100518.03.

6. Akomolafe, A. A.,Maradesa, A. and Yusuf, T. O. (2018): Beta-Binomial Mixture Models: Its Consistence and Efficient Performance over Binomial models. Indo-Iranian Quarterly International Journal. 2(2), pp. 11-23. http://www.iijsr.com.

7. Akomolafe, A. A., (2018): Investigating Customer Behaviour Heterogeneity using Exponential Gamma Timing Model. Rep and Opinion 10(5), pp. 25-31. http://www.sciencepub.net/report. doi: 10:7517/marsroj100518.03

8. Abouammoha, A.M., Alshangitia, A.M., Ragabb, I.E., 2015. A new generalized Lindley distribution.Statistical Computation and Simulation DOI:10.1080/00949655.2014.995101.

9. Akmakyapan, S., Kadlar, G.Z., 2014. A new customer lifetime duration distribution: The Kumaraswamy Lindley distribution. International Journal of Trade, Economics and Finance 5, pp. 441-444.

10. Al-Mutairi, D.K., Ghitany, M.E., Kundu, D., 2013. Inferences on stress-strength reliability from Lindley distributions. Communications in Statistics - Theory and Methods 42, pp. 1443-1463.

11. Alkarni, S.H., 2015. Extended inverse lindley distribution: properties and application. SpringerPlus4, pp. 1-13.

12. Ashour, S.K., Eltehiwy, M.A., 2015. Exponentiated power Lindley distribution. Journal of Advanced Research 6, pp. 895-905.

13. Dumonceaux, R., Antle, C., 1973. Discrimination between the lognormal and weibull distribution.Technometrics 15, pp. 923-926.

14. Elbatal, I., Elgarhy, M., 2013. Statistical properties of Kumaraswamy quasi Lindley distribution.International Journal of Mathematics Trends and Technology 4, pp. 237-246.

15. Ghitany, M., Al-Mutairi, D., Balakrishnan, N., AlEnezi, L., 2013. Power Lindley distributionand associated inference. Computational Statistics and Data Analysis 64, pp. 20-33.

16. Ghitany, M., Atieh, B., Nadarajah, S., 2008. Lindley distribution and its application.Math.Comput.Simul. 78, pp. 493-506

17. Krishna, H., Kumar, K., 2011. Reliability estimation in Lindley distribution with progressively type-II right censored sample. Math.Comput.Simul. 82, pp. 281-294.

18. Lindley, D., 1958. Fiducial distributions and bayes theorem. J. R. Statist. Soc. Ser. B 20, pp.102-107.

19. Mahmoudi, E., Zakerzadeh, H., 2010. Generalized poisson-Lindley distribution. Communications inStatistics - Theory and Methods 39, pp.17851798.

20. Cordeiro, G.M. and M. De Castro. 2011. "A New Family of Generalized Distributions." Journal of Statistical Computation and Simulation 81(7), pp. 883-898. https://doi.org/10.1080/00949650903530745

21. Eugene, N., C. Lee, and F. Famoye. 2002. "Betanormal distribution and its applications" Communications in Statistic:-Theory and methods 31(4), pp. 497-512. doi.org/10.1081/STA120003130.

22. Idowu, B.N., Ikegwu and M. Emmanuel. 2013. "The Beta-Weighted Weibull Distribution: Some Properties and Application to Bladder Cancer Data." Journal of Applied and Computational Mathematics 2: 145. doi: 10.4172/2168-9679.1000145

23. Sharma, V.K., Singh, S.K., Singh, U., Agiwal, V., 2015. The inverse Lindleydistribution: A stress reliability model with application to head and neck cancer data.Journal of Industrial and Production Engineering 32, pp. 162-173.

24. Sharma, V.K., Singh, S.K., Singh, U., Merovci, F., 2014b. The generalized inverseLindley distribution: A new inverse statistical model for the study of upside-downbathtub data. Com- munications in Statistics-Theory and Methods In press, DOI:10.1080/03610926.2014.948206.

25. Singh, B., Gupta, P.K., 2012. Load-sharing system model and its application to the real data set. Mathematics and Computers in Simulation 82, pp.1615-1629.

26. Zakerzadeh, H., Dolati, A., 2009. A generalised Lindley distribution. Journal of math extension 3, pp. 13-25.

\section{Biographical notes}

Akomolafe ,Abayomi Ayodele received a B.sc. in Statistics at University of Ilorin, Nigeria in 1997, M.sc. and PhD. in Statistics (University of Ibadan, Nigeria) in 2004 and 2011 respectively. Since then he has been a university lecturer that specializes in statistical inference, Probability distribution Theory (Hybrid Distribution with application to epidemiological studies, genetic modeling and microarray), Stochastic Process and Sample survey. Having acquired more than 20 years of university teaching experience, he is presently an Associate Professor at the Federal University of Technology Akure (FUTA), Nigeria. 